\title{
Status epilepticus and diabetes ketoacidosis: uncommon clinical presentations of acromegaly
}

\author{
Nyasatu G Chamba®1,2, Ahlam A Amour3, Abid M Sadiq 1,2, Tecla R Lyamuya1, \\ Emmanuel V Assey ${ }^{1}$, Adnan M Sadiq ${ }^{2,4}$ and William P Howlett ${ }^{1,2}$
}

1Department of Internal Medicine, Kilimanjaro Christian Medical Centre, Moshi, Tanzania, 2Kilimanjaro Christian Medical University College, Moshi, Tanzania, ${ }^{3}$ Mnazi Mmoja Hospital, Zanzibar, Tanzania, and ${ }^{4}$ Department of Radiology, Kilimanjaro Christian Medical Centre, Moshi, Tanzania
Correspondence should be addressed to N G Chamba

Email

nyasatuchamba@yahoo.com

\section{Summary}

Acromegaly is a rare disease caused by hypersecretion of the growth hormone (GH). Most cases are caused by either pituitary microadenoma or macroadenoma. The GH producing tumors present with clinical manifestations of acromegaly due to excessive $\mathrm{GH}$ secretion or symptoms resulting from mass effects of the enlarging tumor. The physical changes are usually slow and, therefore, recognition of the disease is delayed. These adenomas are never malignant but can have significant morbidity and mortality. A subgroup of patients with acromegaly present with severe hyperglycemia resulting in diabetic ketoacidosis (DKA) which requires insulin. Rarely are pituitary tumors responsible for generalized convulsions except when they are too large. We hereby present two cases, the first is that of a 26 -year-old female who presented with new onset status epilepticus, DKA with a 1-year history of diabetes mellitus (DM). On examination, she had clinical features of acromegaly. The second case is that of a 34-year-old female who presented with new onset status epilepticus, hyperglycemia with a history of recently diagnosed DM, and features of gigantism. In both cases, their diagnosis was confirmed by elevated serum GH and later by elevated insulin-like growth factor type 1 levels, and CT of the head demonstrating large pituitary macroadenoma. The importance of clinical history and examination, as well as investigations is vital in the recognition of acromegaly. The prognosis of acromegalic patients depends on early clinical recognition and tumor size reduction by either medical or surgical therapy.

\section{Learning points:}

- Conditions such as status epilepticus and DKA may be clinical presentations in patients presenting with acromegaly.

- Seizures are rare in people with pituitary adenoma and typically occur when the tumor invades the suprasellar area due to mass effect on the brain.

- This article shows how best we were able to manage the acromegaly complications in a low resource setting.

- Hyperprolactinemia in acromegaly may be due to disruption of the normal dopaminergic inhibition of prolactin secretion due to mass effect of the macroadenoma, and around $25 \%$ of GH-secreting adenomas co-secrete prolactin. 


\section{Background}

Acromegaly is a rare clinical condition resulting from excessive secretion of growth hormone (GH), which stimulates excessive production of insulin-like growth factor type 1 (IGF-1). Most cases are caused by a GH secreting pituitary adenoma and few by a hypothalamic or neuroendocrine tumor (1).

Due to the tumor mass effect and the prolonged effects of GH and IGF-1 hypersecretion, there is a multiorgan involvement. The tumor can cause headaches and visual field defects. The effects of hypersecretion mainly cause morphological changes such as enlarged facial features, enlarged hands and feet. Other manifestations include cardiovascular diseases, metabolic dysfunction, osteoarticular disorders, respiratory disorders, reproductive dysfunction and gastrointestinal manifestations (2).

Diabetes mellitus (DM) may develop in up to about $35 \%$ of acromegalic patients due to insulin resistance caused by excess GH and IGF-1, and up to $50 \%$ with glucose intolerance (3). Excess GH and IGF-1 can induce insulin resistance directly in the liver, adipose tissue and muscle, resulting in increased endogenous glucose production, decreased muscle glucose uptake and rising blood glucose (4). Patients who presented with DM in acromegaly have a longer duration of the disease prior to diagnosis suggesting a longer duration of exposure to excess GH and IGF-1 leading to glucose intolerance (5). DM completely resolves in two-thirds of patients whose acromegaly is cured by surgery, but the rest continue to have some impaired glucose intolerance.

\section{Case presentation}

\section{Case 1}

A 26-year-old female presented to the emergency department with a sudden onset of repeated generalized tonic-clonic seizures associated with tongue biting and urine incontinence which started on the morning of admission. The last three episodes of seizures were observed at the emergency department, each lasting about 5-10 min, with an interval of 2-3 min between the attacks. On admission, she was restless and acidotic with Kussmaul breathing. On recovery, she reported an increasingly severe headache associated with loss of vision which had started 9 months previously. A year prior to admission, she had been diagnosed with DM requiring insulin. In addition, she reported progressive enlargement of her hands, feet and face which had started 3 years previously and was amenorrhoeic for the same duration.
On general examination, she was of large stature weighing $110 \mathrm{~kg}$ with a BMI of $34.3 \mathrm{~kg} / \mathrm{m}^{2}$. She was noted to have a prominent lower jaw, large tongue, enlarged hands and feet with hypopigmented palms and soles (Fig. 1). On neurological examination, she had homonymous hemianopia to her right visual field with light perception only in the left eye and ability to read medium-sized print in the right eye. The left pupil was constricted, not reacting to light but normal afferent pupil reflex. On fundoscopic examination (Fig. 2), there was optic atrophy bilaterally but more marked on the left. The rest of her neurological examination was normal.

\section{Investigation}

On admission, her random blood glucose was 27.2 $\mathrm{mmol} / \mathrm{L}$ and urine dipstick showed ketones of 3+. Other results were hemoglobin $15.8 \mathrm{~g} / \mathrm{dL}$, HbA1c $15 \%$, serum bicarbonate $17 \mathrm{mEq} / \mathrm{L}$, serum cholesterol $8.2 \mathrm{mmol} / \mathrm{L}$ and low-density lipoprotein $5.3 \mathrm{mmol} / \mathrm{L}$. GH level was elevated to $20.5 \mathrm{ng} / \mathrm{mL}$ (normal range (NR): 1-14 ng/mL). The CT scan of the head revealed an enhancing sellarsuprasellar mass with intralesional necrosis and widening of the sella turcica. The mass extended superiorly anterior to the 3rd ventricle and the foramen of Monroe with hemorrhage extending into the right frontal lobe. The radiological features were consistent with a diagnosis of a large pituitary macroadenoma (Fig. 3).

\section{Treatment}

She was treated initially with $900 \mathrm{mg}$ of oral phenytoin and maintained on $300 \mathrm{mg}$ of oral phenytoin. She was also treated with soluble insulin and i.v. fluids. The insulin doses were titrated according to her blood glucose levels, whereby her diabetes required unusually high doses of insulin.

\section{Outcome and follow-up}

She was referred for a neurosurgical opinion for further evaluation of the pituitary tumor. She was started on somatostatin receptor ligand (SRL), and her follow-up review found a reduction in IGF-1 levels from 519 to 431 $\mu \mathrm{g} / \mathrm{L}$ (NR: 116-324) after 6 months on medical therapy.

\section{Case 2}

A 34-year-old female presented to the emergency department with repeated generalized tonic-clonic 


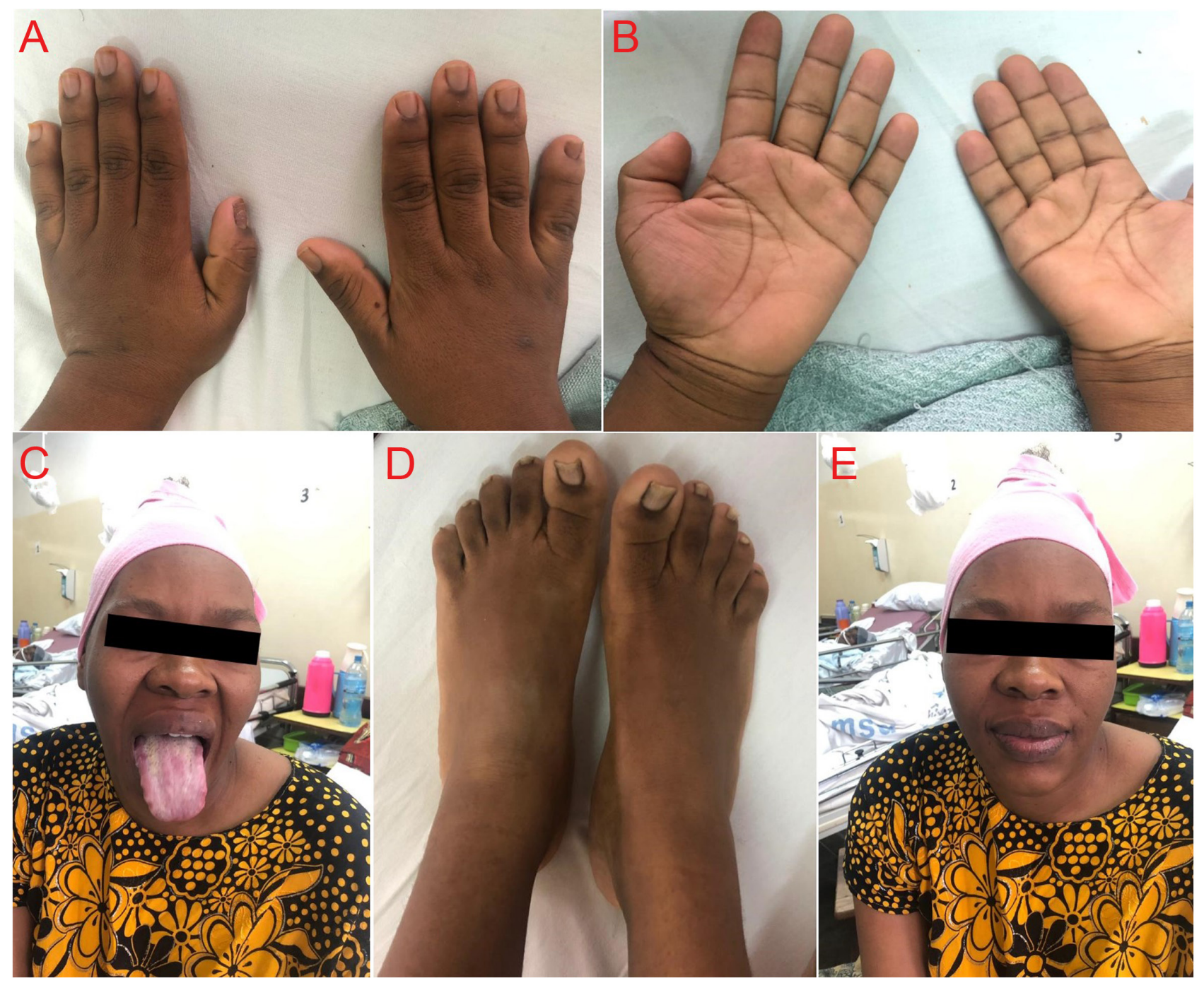

\section{Figure 1}

Image A and image B show huge spade-like hands. Image C shows macroglossia with teeth ridges on the sides and bitten tongue due to the seizures. Image D shows large feet. Image E shows prominent supraorbital ridges and thick lips.

seizures of focal onset associated with tongue biting and urine incontinence. The seizures had first started 5 days previously but were observed to be lasting for approximately $5 \mathrm{~min}$ and recurring every $30 \mathrm{~min}$. She had a history of recently diagnosed DM which had been controlled on oral hypoglycemic agents. On recovery, she reported a history of progressively increasing headache which had started 8 months previously and an enlarged right breast which was lactating. She was amenorrhoeic for the previous 12 months.

On general examination, she was of large stature, weighing $122 \mathrm{~kg}$ with a BMI of $33.7 \mathrm{~kg} / \mathrm{m}^{2}$. The right breast was noted to be enlarged and lactating with no palpable mass. There was no notable enlargement of the face, hands or feet, apart from being tall and obese.
Neurological examination revealed a lower motor neuron facial nerve palsy on the right side. Fundoscopy was normal.

\section{Investigation}

On admission, her random blood glucose was $16.0 \mathrm{mmol} / \mathrm{L}$ and urine dipstick was negative for ketones. Other results showed hemoglobin: $15.0 \mathrm{~g} / \mathrm{dL}$, HbA1c: $11.3 \%$, serum bicarbonate: $25 \mathrm{mEq} / \mathrm{L}$, serum cholesterol: $4.6 \mathrm{mmol} / \mathrm{L}$ and low-density lipoprotein: of $2.7 \mathrm{mmol} / \mathrm{L}$. GH levels and prolactin levels were $17.5 \mathrm{ng} / \mathrm{mL}$ and $165.42 \mathrm{ng} /$ $\mathrm{mL}(\mathrm{NR}:<25 \mathrm{ng} / \mathrm{mL}$ ), respectively. The CT scan of the head revealed a large enhancing well-defined hyper-dense predominantly solid space-occupying mass lesion in the 


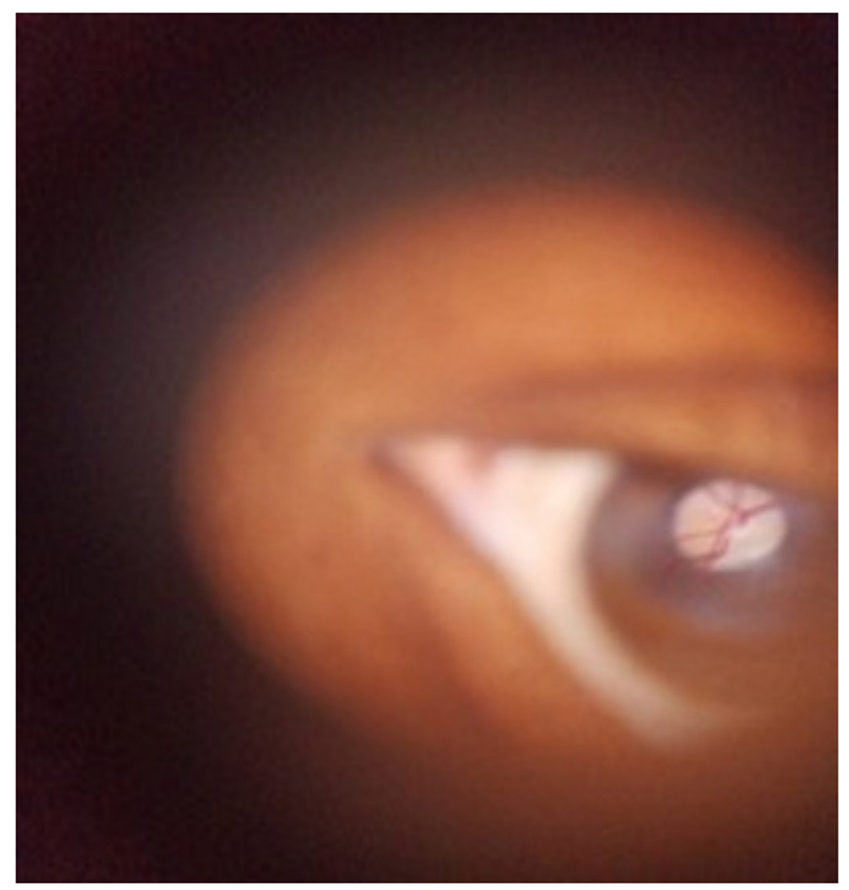

Figure 2

Fundoscopic examination shows optic nerve atrophy.

suprasellar region with a widening of the sella turcica and minimal surrounding edema. The radiological features were consistent with a diagnosis of a large pituitary macroadenoma (Fig. 4).

\section{Treatment}

She was treated initially with $900 \mathrm{mg}$ of oral phenytoin and her seizures were controlled on oral phenytoin 300 mg together with carbamazepine $400 \mathrm{mg}$ twice daily. She was given insulin and was later controlled on glimepiride $2 \mathrm{mg}$ twice daily.

\section{Outcome and follow-up}

Arrangements were made for a neurosurgical opinion concerning her longer-term management. She was initiated on bromocriptine $1.25 \mathrm{mg}$ daily, and her follow-up review found a slight reduction in IGF-1 levels from 463 to $407 \mu \mathrm{g} / \mathrm{L}$ (NR: 112-300) after 3 months of medical therapy.

\section{Discussion}

The presenting complaint in both case reports was that of new-onset seizure disorder with status epilepticus complicated by DKA in the first patient and hyperglycemia in the second patient. Notably, DM had been diagnosed relatively recently in both patients. The underlying cause in both was pituitary macroadenoma with elevated $\mathrm{GH}$ levels and with clinical features of acromegaly in the first case. Patients with pituitary macroadenoma typically present with clinical endocrinological and neurological effects, as illustrated in both these case reports.

The main endocrine effects in the first patient were obesity, acromegaly, diabetes and amenorrhea with an elevation in her GH and IGF-1 levels. Although the second patient did not have features of acromegaly, she had marked obesity, DM, breast enlargement, lactation and amenorrhea. Notable, her GH, IGF-1 and prolactin levels were elevated. While hyperprolactinemia in acromegaly may be due to disruption of the normal dopaminergic inhibition of prolactin secretion due to mass effect of the macroadenoma, around 25\% of GH-secreting adenomas co-secrete prolactin (6). DM was diagnosed previously in both patients and is known to occur in up to one-third of acromegaly patients. DKA is a rare feature of acromegaly due to insulin reserves with hepatic ketogenesis (7). Ketoacidosis can be explained by glucotoxicity causing partially reversible $\beta$-cell dysfunction (8).

The neurological effects reported in both patients included headaches, new-onset seizures and cranial nerve palsies including asymmetrical loss of vision and acuity in the first patient and facial nerve palsy in the second patient. The main neurological effects of macroadenoma are related to the effects of the slow-growing tumor compressing or invading the adjacent brain and cranial

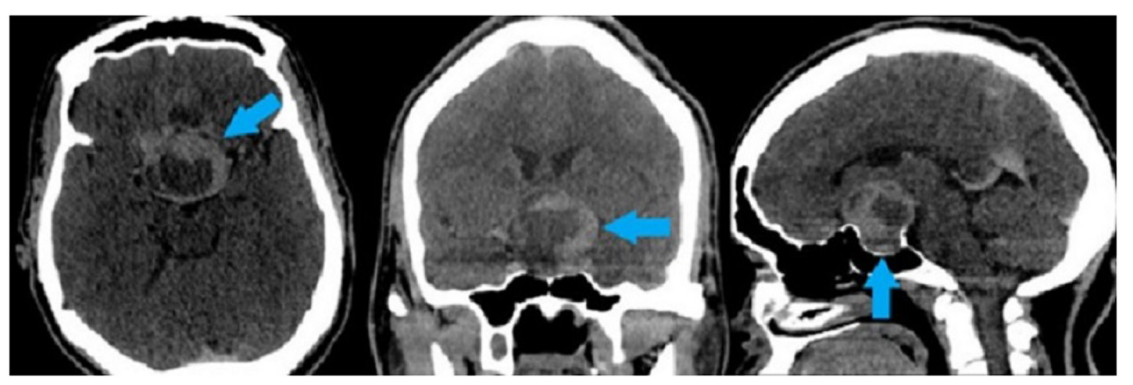

Figure 3

Axial CT brain view shows sella mass (left blue arrow). Coronal CT brain view shows sella mass (middle blue arrow). Sagittal CT brain view shows sella mass (right blue arrow). 


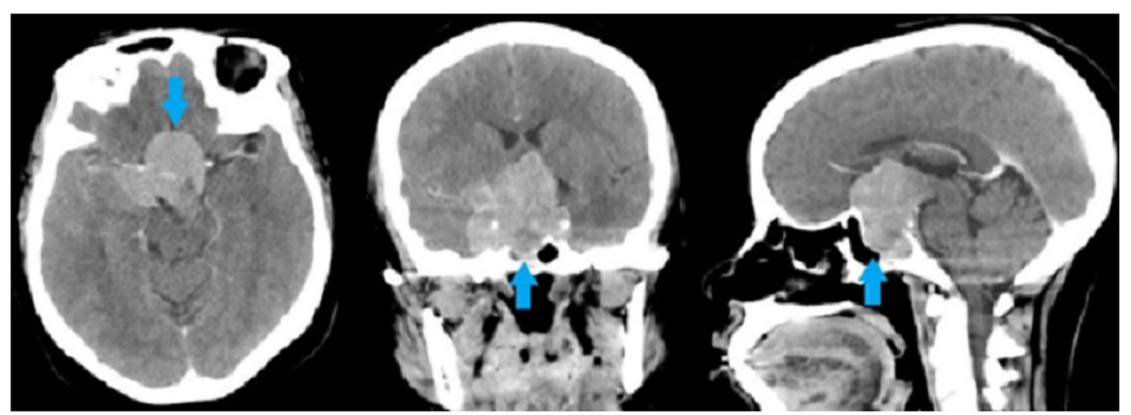

\section{Figure 4}

Axial CT brain view shows sella mass (left blue arrow). Coronal CT brain view shows sella mass (middle blue arrow). Sagittal CT brain view shows sella mass (right blue arrow).

nerves (1). Both patients in this report presented with new onset seizure disorders presenting as status epilepticus. Seizures are rare in people with pituitary adenoma as they account for only $4 \%$ of all intracranial tumors causing seizures (9). They typically occur when the tumor invades the suprasellar area due to mass effect on the brain in large pituitary adenomas (9). The mechanism by which status epilepticus may occur in patients with pituitary macroadenoma is by local effect and hormone dysfunction (10). The seizure disorder in the first case is likely to have been secondary to the small acute hemorrhage reported in the right frontal lobe which in turn may have been secondary to the acute infarction reported in the macroadenoma. Notably, the second case had brain edema around the pituitary macroadenoma.

The previous mainstay of management of acromegalic patients used to be surgical removal of the macroadenoma, but current literature states that medical management should be the first-line therapy (11). Though surgery is the only treatment that results in immediate disease remission (6). Medical therapy is based on either SRLs, dopamine agonists or $\mathrm{GH}$ receptor antagonists. Disease remission can be achieved in up to $40 \%$ of patients on SRLs and up to $97 \%$ on $\mathrm{GH}$ receptor antagonists. Radiation therapy can reduce tumor volume of $>90 \%$ of cases but at the cost of many side effects (6).

Different treatment modalities can exert different effects on glucose metabolism in patients with acromegaly. $\mathrm{DM}$ is not reversible in some patients despite biochemical control of acromegaly. Although surgery and pegvisomant exert beneficial effects, the effects of SRLs vary between patients (6). SRL treatment improves disease control but reduces insulin levels and increases HbA1c levels without affecting fasting glucose levels (12). Acromegaly-induced seizures are usually resistant to symptomatic treatment by antiepileptic drugs but respond to medical treatment that reduces pituitary adenoma (9). Total resection of the tumor and/or dopamine agonists reduce the recurrence of the status epilepticus.
In conclusion, life-threatening conditions such as status epilepticus and DKA may be clinical presentations in patients presenting with acromegaly and with clinical features of pituitary macroadenoma. The case reports illustrate the importance of history taking, physical examination and investigations in their recognition and management. Increased awareness, early recognition and diagnosis will help facilitate their management and avoid complications.

\section{Declaration of interest}

The authors declare that there is no conflict of interest that could be declared as prejudicing the impartiality of the research reported.

\section{Funding}

This research did not receive any specific grant from any funding agency in the public, commercial or not-for-profit sector.

\section{Patient consent}

Written informed consent was obtained from both the patients for the publication of this case report and the accompanying images.

\section{Acknowledgements}

The authors thank both the patients for their patience and co-operation.

\section{References}

1 Katznelson L, Laws ER, Melmed S, Molitch ME, Murad MH, Utz A, Wass JA \& Endocrine Society. Acromegaly: an endocrine society clinical practice guideline. Journal of Clinical Endocrinology and Metabolism 201499 3933-3951. (https://doi.org/10.1210/jc.20142700)

2 Caron P, Brue T, Raverot G, Tabarin A, Cailleux A, Delemer B, Renoult PP, Houchard A, Elaraki F \& Chanson P. Signs and symptoms of acromegaly at diagnosis: the physician's and the patient's perspectives in the ACRO-POLIS study. Endocrine 201963 120-129. (https://doi.org/10.1007/s12020-018-1764-4)

3 Hannon AM, Thompson CJ \& Sherlock M. Diabetes in patients with acromegaly. Current Diabetes Reports 201717 8. (https://doi. org/10.1007/s11892-017-0838-7) 
4 Møller N, Schmitz O, Jøorgensen JO, Astrup J, Bak JF, Christensen SE Alberti KG \& Weeke J. Basal- and insulin-stimulated substrate metabolism in patients with active acromegaly before and after adenomectomy. Journal of Clinical Endocrinology and Metabolism 1992 74 1012-1019. (https://doi.org/10.1210/jcem.74.5.1569148)

5 Fieffe S, Morange I, Petrossians P, Chanson P, Rohmer V, Cortet C, Borson-Chazot F, Brue T, Delemer B \& French Acromegaly Registry. Diabetes in acromegaly, prevalence, risk factors, and evolution data from the French Acromegaly Registry. European Journal of Endocrinology 2011164 877-884. (https://doi.org/10.1530/EJE-101050)

6 Gadelha MR, Kasuki L, Lim DST \& Fleseriu M. Systemic complications of acromegaly and the impact of the current treatment landscape: an update. Endocrine Reviews 201940 268-332. (https:// doi.org/10.1210/er.2018-00115)

7 Chen YL, Wei CP, Lee CC \& Chang TC. Diabetic ketoacidosis in a patient with acromegaly. Journal of the Formosan Medical Association 2007106 788-791. (https://doi.org/10.1016/S0929. 6646(08)60042-X)
8 Palakawong P \& Arakaki R. Diabetic ketoacidosis in acromegaly: A case report. Endocrine Practice 2012 In press. (https://doi.org/10.4158/ EP12189.CR)

9 Chentli F, Akkache L, Daffeur K \& Azzoug S. General seizures revealing macro-adenomas secreting prolactin or prolactin and growth hormone in men. Indian Journal of Endocrinology and Metabolism 201418 361-363. (https://doi.org/10.4103/2230-8210.131185)

10 Lindbom U, Hulting AL \& Tomson T. Paradoxical GH response to TRH during status epilepticus in man. European Journal of Endocrinology 1999140 307-314. (https://doi.org/10.1530/eje.0.1400307)

11 Puig-Domingo M \& Marazuela M. Precision medicine in the treatment of acromegaly. Minerva Endocrinologica 201944 169-175. (https://doi.org/10.23736/S0391-1977.18.02937-1)

12 Cozzolino A, Feola T, Simonelli I, Puliani G, Pozza C, Giannetta E, Gianfrilli D, Pasqualetti P, Lenzi A \& Isidori AM. Somatostatin analogs and glucose metabolism in acromegaly: A meta-analysis of prospective interventional studies. Journal of Clinical Endocrinology and Metabolism 2018103 2089-2099. (https://doi.org/10.1210/ jc.2017-02566)

Received in final form 28 March 2021

Accepted 13 April 2021 